\title{
Where is the leadership we need?
}

\author{
Fiona Godlee editor in chief
}

The BMJ

The BMA's decision to call off next week's five day strike by junior doctors in England has been widely greeted with a sigh of relief. The BMA says it acted after it was contacted last week by thousands of its members worried that the strike would put patients at risk (doi:10.1136/bmj.i4844).

This sensible decision restores a degree of professionalism to a sorry and damaging saga. But, asks Andy Cowper (doi:10. 1136/bmj.i4846), will public sympathy for the juniors outlast the government's determination to enforce the new contract? Is this still a contractual dispute, or has it morphed into a political attack on the government's policies? What changes to the contract would satisfy doctors' leaders? And has the gradual drift back to work as usual begun?

Should the BMA re-ballot its members before moving ahead with further strike action? The remaining contractual issues (doi:10.1136/bmj.i4841) do not on the face of it justify such escalation. But junior doctors are demoralised, overstretched, and undersupported. What's more, says David Oliver (doi:10. $1136 / \mathrm{bmj} . \mathrm{i} 4656$ ), they see what's in store for them if and when they become consultants, and it's not looking pretty. "This dispute is in essence emotional," says Richard Thomson (doi:10. 1136/bmj.i4845). And these wider issues at the heart of the dispute are only likely to get worse as NHS finances deteriorate under the current government.

Today's 55000 junior doctors are tomorrow's senior clinicians, medical educators, researchers, policy makers, political leaders, and, I would like to believe, trust chief executives. Allowing them to become, as Victoria Ewan says (doi:10.1136/bmj.i4845), "scapegoats for an underfinanced seven day NHS" serves no one.

The NHS is at one of its lowest ebbs in its history. Doctors hold a unique place within it and within the national psyche. If we stand by as underfunding fulfils its detractors' prophecies that it can't cope with rising demand, history will not easily forgive us. The latest dead canary in the mine is news that two CCGs are telling GPs to ask patients to use private insurance if they have it (doi:10.1136/bmj.i4848), taking us one small but important step closer to an insurance based model.

But what should we do? Margaret McCartney has a proposal (doi:10.1136/bmj.i4745). We need, she says, "a protest that involves all doctors, which is sustainable, and which will not harm (and may even benefit) patients. It should harm only the political policy making that damages the NHS." Her suggestion is to stop doing things that add no value to the care of patients, including non-evidence based appraisal, CQC inspections, and paperwork.

However flawed, the NHS is a national asset admired around the world, if never yet imitated. It is a socially progressive, cost effective, and civilising force. Supporting it is not a party political position. As a profession we should demand that our leaders - the BMA and the royal colleges-now act together to lift us out of a damaging and unproductive industrial dispute and instead promote an urgent national debate on the future of this precious public good.

Allowing junior doctors to become "scapegoats for an underfinanced seven day NHS" serves no one 